\title{
Syrian Refugee Families with Young Children: An Examination of Strengths and Challenges During Early Resettlement
}

\author{
Sophie Yohani \\ University of Alberta \\ sophie.yohani@ualberta.ca \\ Larissa Brosinsky \\ University of Alberta \\ brosinsk@ualberta.ca \\ Anna Kirova \\ University of Alberta \\ akirova@ualberta.ca
}

\begin{abstract}
With the arrival of a large number of Syrian families to Canada, educators and other service providers are reflecting on best practices to support the psychosocial adaption of refugees from conflict settings. This article draws on a study that examined the psychosocial adaptation of Syrian refugee families with young children in Western Canada, and uses the RAISED Between Cultures framework to discuss their strengths and identified barriers during early resettlement. Using a community-based participatory research approach and critical incident method, the study involved focus groups and semi-structured interviews with ten Arabic-speaking cultural brokers who were working with Syrian refugee families using holistic supports during early resettlement. Data were analyzed thematically both across and within 10 cases, then examined in light of six factors that contribute to refugee children's outcomes as identified in the RAISED Between Cultures framework. As key figures in refugee children and families' adaptation to their host country, educators can draw on these findings to identify families' and children's'strengths and challenges during early resettlement to ensure positive child outcomes.
\end{abstract}

\section{Introduction}

Reflecting one of the largest humanitarian crises in recent history, the Syrian conflict has resulted in the displacement of close to 6 million individuals, over half who are children under the age of 18 (UNHCR, 2018). As one of the western resettlement countries for refugees, Canada received over 52, 000 Syrian refugees between November 2015 and March 2018 (Immigration, Refugees \& Citizenship Canada, 2018). Similarly, children under the age of 15 years represented close to half of the resettled Syrians (Citizenship and Immigration Canada, 2017). In Canada, most of the Syrian refugees arrived as family units and were resettled in major urban areas. For example, in Alberta where this study took place, 1,025 families (i.e., 3,700 individuals) were admitted between November 2015 and August 2016 (Citizenship and Immigration Canada, 2017).

Journal of Contemporary Issues in Education, 2019, 14(1), pp. 13-32. 
The development and wellbeing of young refugee children is put at risk by exposure to adverse experiences such as the loss of and separation from family members, displacement, and other conflict-related traumas (Bates et al., 2005; Klingman, 2002). Once in resettlement countries, refugee children and their families may continue to experience adversity that can negatively impact settlement and integration (Immigration, Refugees \& Citizenship Canada, 2016). Families with young children in particular can face barriers accessing and utilizing health services, early childhood programs, parenting resources, and family supports (Kirova, 2010).

Yet, it is also well documented that children's resilience in the face of adversity, is greatly influenced by the protective role of family and community supports (Kanji \& Cameron, 2010; Tol, Song, \& Jordans, 2013). Schools, as critical settings for children's academic, social and emotional development, are also critical sites for refugee children's integration into new countries. Consequently, educators and other school personnel can play a crucial role in mitigating risks that refugee children encounter and support resilience and development. This article draws on the RAISED Between Two Cultures conceptual model (Georgis et al., 2017) to examine the strengths and challenges that refugee families with young children encounter and what early childhood educators can do to ensure positive outcomes for children and their families in resettlement countries. It is based on a study examining the psychosocial adaptation of Syrian families with young children that took place during the early resettlement on Syrians in Alberta, Canada.

\section{Psychosocial Adaptation of Young Refugee Children in Educational Contexts}

Refugee children who have been exposed to conflict and displacement enter the education system in resettlement countries with unique challenges and needs. In addition to the usual migration challenges associated language and cultural barriers, this child population is likely to have encountered trauma in the form of threats to safety, relationships, identity and human rights violations (Betancourt et al., 2012; Yohani, 2015). For example, a few studies have already documented mental health impacts of the Syrian crisis on children to include psychosomatic symptoms, depression, and Post Traumatic Stress Disorder (PTSD) (Hadfield, Ostrowski, \& Ungar, 2017; Hassan et al., 2015; Özer, Şirin, \& Oppedal, 2013; Soykoek, Mall, Nehring, Henningsen, \& Aberl, 2017). Given that young children's emotional wellbeing is highly dependent on that of their caregivers, refugee parent mental health is an area of concern (McFarlane, Kaplan, \& Lawrence, 2011; Saile, Ertl, Neuner, \& Catani, 2014) and can also indirectly influence children's well-being and adaptation (Betancourt \& Khan, 2008; Henley \& Robinson, 2011). While more research is needed in this area in relation to Syrians, emerging research suggests some Syrian parents have struggled with mental health challenges including depression and anxiety amongst women who were pregnant or post-partum (Ghumman, McCord, \& Chang, 2016) and general psychological distress in the form of nervousness, sleep difficulties, hopelessness, anger and panic (Ahmed, Bowen, \& Xin Feng, 2017). Other settlement-related challenges that parents of refugee children are contending with include finding adequate housing, unemployment, and limited access to appropriate healthcare (Carter \& Osborne, 2009; Lake, 2016). Educators who are cognizant of psychosocial impacts of refugee experiences on children and their families will be better equipped to identify and refer them to appropriate services. 
Language poses a significant barrier to the educational adaptation of refugee children. Language plays a key role in both making and communicating meaning about the world, therefore, identifying the unique challenges faced by linguistic minority children as they enter the school system, needs special attention by educators. Many children enter the education institutions too young to be fluent speakers of their home language, and as a result lose the little they know of their home language very quickly. Those who enter educational contexts fluent in their home languages are often quickly discouraged from using it by the intentional or unintentional messages they receive from both the adults and their peers in these environments. Children interpret these messages to mean that only the "official" language of the school is the legitimate one and are forced to adapt to the majority language environment. "[A]ssimilationist submersion education where indigenous and minority children are taught through the medium of dominant languages, causes mental harm and often leads to the students using the dominant language with their own children later on, i.e. over a generation or two the children are linguistically and often in other ways too forcibly transferred to a dominant group" (Skutnabb-Kangas, 2002).

Furthermore, the loss of their home language has harmful effects on their relationships with their extended family, such as grandparents, and sometimes with their parents, if the family has recently immigrated and the parents are at the very beginning of learning the dominant language of the host country (Cummins, 1991; Wong Fillmore, 1991). Despite evidence in support of conceptual and academic skill transfer across languages becoming more readily available, educational systems around the globe "failed to address in a sufficiently positive way the dual language reality of emergent bilingual children" (Cummins, 2012, p. 10).

Although a signatory of the 1989 United Nations Convention on the Rights of a Child, Canada is yet to protect the linguistic rights of linguistic minorities or persons of Indigenous origin as stated in Article 30 of the Convention:

In those States in which ethnic, religious or linguistic minorities or persons of Indigenous origin exist, a child belonging to such a minority or who is indigenous shall not be denied the right, in community with other members of his or her group, to enjoy his or her own culture, to profess and practice his or her own religion, or to use his or her own language. (OHCHR, 2019)

Given the complexity and multiplicity of the needs often faced by refugee families, teachers and school personnel often feel inadequately prepared to work with this child population. This article responds to this need by providing a framework (i.e. RAISED Between Cultures) that can guide early childhood educators in identifying both the challenges and strengths of these families within the educational context. It examines some of the strengths and challenges encountered by Syrian families with young children that were identified in a research project conducted by the authors to examine the psychosocial adaptation of families with young children during first years of resettlement. By highlighting the examples from this recent research project, the goal is to illustrate the utility of the framework for assisting educators and other school personnel to interrupt well established practices that attempt to "fix" those who are deemed different and therefore deficient/other/abnormal by the education system through curricula and pedagogical interventions. It points educators' attention to the fact that "[T] he processes by which persons belonging to a particular group are seen by a more powerful group as abnormal" (Heydon \& Iannacci, 2009, p. 3) are now understood as pathologizing. Children from culturally and linguistically diverse backgrounds and those who are dis/abled are most commonly pathologized. 


\section{Theoretical Framework}

This article draws on two ecological systems frameworks to examine the adaptation of families with young children: The Ecological Systems Model (Bronfenbrenner, 1994) and The RAISED between Cultures model (Georgis et al., 2017). Both models attend to the interaction between people and their environments as critical elements in shaping experience and associated outcome.

\section{Ecological Systems Model}

Bronfenbrenner's (1979) theory illustrates the various environments that influence child development and is often represented as concentric nested circles. Each circle represents one of four systems (microsystem, mesosytem, exosystem and macrosystem) and is reciprocally related to its neighbor with more direct influence on the child by proximal systems. For example, young children are more directly influenced by and influence their families. Parents' behavior at home is influenced by their experiences at work and in their communities, while the society in which the community exists shapes and is shaped by its members. The combination of subjective (i.e. personal) factors and objective (environmental) factors strongly influence development during formative years from early infancy to young adulthood. Reciprocal interactions between a developing child and persons, objects, and symbols in the external environment, contribute to development through processes of progressively more complex interactions that occur on a regular basis over extended periods of time (Bronfenbrenner \& Ceci, 1994). For younger children in particular, this interactive process over time generates the knowledge, ability, and skills to engage in similar activities in other contexts. According to Bronfenbrenner's theory, the energy that drives the proximal processes is said to come from subjective elements of experience (Bronfenbrenner \& Evans, 2000; Bronfenbrenner \& Morris, 1998). That is, interactions between people and their environment are strongly influenced by individual or personal factors. In other words, interactions in early childhood relationships produce emotional impacts which continue throughout childhood affecting how people relate to themselves and others. Subjective elements of experience are also applied to activities one engages in, such as learning at school, and are characterized by both stability and change. Research points out that positive and negative subjective forces emerging from the past can also contribute strongly towards how a person develops in the future (Bronfenbrenner \& Morris, 1998).

Despite its applicability to most contexts as it provides a broad theoretical framework within which practice-based models can be developed, one of Bronfenbrenner's theory's major weaknesses is its lack of adequate dealing with issues of culture. While indirectly referred to in the macrosystem, the influence of culture on children's development is not emphasized in Bronfenbrenner's model. It does not consider the fact that "cultural groups have values, beliefs, lifestyles and patterns of social exchange different from those found in North American middleclass communities" (Tudge, 2008, p. 73). In addition, Bronfenbrenner's theory does not provide specific guidance regarding psychosocial adaptation or outcomes in the aftermath of trauma and displacement such as experienced by refugees from conflict zones (Yohani, 2015). The proposed RAISED model is a cultural-ecological model that has at its core the view of culture as "the everyday life, the everyday dramas, events, and activities in which individuals participate, by themselves and with others"... and that are "intertwined within the contexts in which they take 
place" (Tudge, 2008, p. 73). It is therefore of grave importance to recognize that immigrant and refugee children may be influenced by the "cultures" of several contexts prior to reaching their resettlement destination.

Recognizing culture as a driving force of all children's development, and putting it at the forefront in the unique situation of development of immigrant and refugee children means to acknowledge that these children are simultaneously socialized in at least two cultural contexts: (a) the heritage culture of their parents, which governs their home and ethnic community lives; and (b) the culture of the country in which they live, and which they encounter in the institutions (e.g. childcare, schools). Socialization is defined as "[T]he process through which children acquire the beliefs, values, practices, skills, attitudes, behaviors, ways of thinking, and motives of their culture that together help children develop into effective and contributing members of the group" (Gauvain \& Parke 2010, p. 239). Immigrant and refugee children need to become familiar with the language, beliefs, and behaviors of both their heritage and majority cultures in order to "have a sense of belonging and be able to participate successfully within both" (Oppedal, 2006, p. 97). The challenges these children face come from the different, sometimes conflicting goals of their families and their schools as socialization agents. It is therefore critical that educators are cognizant of cultural worlds of their students and the challenges they may face navigating them.

\section{RAISED Between Cultures Model}

The RAISED between Cultures model builds on the ecological systems theory and was designed to assist educators and practitioners to work more holistically with children of immigrant and refugee backgrounds (Georgis et al., 2017). This model was created as a collaborative effort among academics, immigrant service providers, working directly with ethnocultural communities, educators and policy-makers with the intention of supporting the development of a set of best practices for working with this population based on what is currently known in the academic and research literature. The intention of the model, therefore was to inform future early childhood practice (Brosinsky, Georgis, Gokiert, Mejia, \& Kirova, 2018). We chose to use this conceptual model to critically examine the results of our larger study on psychosocial adaptation of Syrian families, as a way to explore the applicability of the model as a theoretical framework to this work. As well we wanted to understand the specific issues faced by the Syrian refugees in the early stages of adaption to their host country, and how the use of the model can help teachers better meet the complex needs of refugee children and their families.

The RAISED between Cultures model outlines six important factors that, when considered by educators both together and independently, can contribute to children's outcomes, and which make up the RAISED acronym: Reveal culture, Acknowledge pre-migration experiences, Identify post-migration systemic barriers, Support family and community strengths, Establish connections between environments, and Determine child outcomes together with families. This article illustrates the strengths and barriers faced by refugee families with young children identified in our community-based participatory study that can be understood in terms of the factors identified in this model. 


\section{Methodology}

\section{Community-based Participatory Research}

Community-based participatory research (CBPR) is an approach that is centered on principles of collaboration, reflection, the co-creation of principles of knowledge co-creation and action (Allman, Myers, \& Cockerill, 1997; Israel et al., 2003). Our study involved a collaboration with the Multicultural Health Broker's Cooperative (MCHB), a community-based immigrant serving organization located in Edmonton, Alberta. This organization utilizes cultural brokers, individuals who perform the act of bridging, linking, or mediating between groups or persons of differing cultural backgrounds for the purpose of bringing about change and reducing conflict (Jezewski, 1990) to support the resettlement and integration of refugee and immigrant families. MCHB has over 90 trained cultural brokers who provide services to 62 linguistic and ethnic groups in Edmonton and surrounding areas via four key roles: cultural liaising, mediating, advocacy and relationship building. The study aligned with CBPR principles as it emerged from existing relationships and work being conducted with research team members. Particular to Syrian refugees, one of the authors (Yohani) had provided monthly training (September 2015 to October 2016) to cultural brokers on trauma-informed practice to support families' adaptation. The other two authors (Kirova and Brosinsky) have worked closely with the collaborating organizations to develop the RAISED between Cultures model.

\section{Research Participants and Data Collection Activities}

As noted earlier, this article draws on our larger study that focused on documenting the needs and challenges faced by newly arrived Syrian refugee families with young children, and how cultural brokering can support their psychosocial adaptation as part of the integration process (for a detailed review of the project and methodology see Yohani et al., 2019).

Briefly, using purposive sampling, 9 Arab-speaking cultural brokers responded to the research invitation and gave written consent to participate in all aspects of the project, which included focus groups and individual interviews. Seven participating cultural brokers were of Middle Eastern descent and two were from African countries. All were women and had a range of experience with cultural brokering between 1 and 18 years. At the time of the project, each broker supported approximately 15 Syrian families who had been in Canada from three months to 2 years. Cultural brokers were asked to pay special attention to their experiences of working with families with multiple young children (i.e., 0-8 years) including their psychosocial needs and challenges experienced by Syrian refugee families.

\section{Data Collection: Critical Incidents}

Focus groups using critical incidents. Five focus groups were conducted with the cultural brokers using critical incidents method (Flanagan, 1954; Yohani, 2013). Cultural brokers were instructed to select two unique critical incidents that highlight a situation that worked well and a situation that was very challenging in their work with the newly arrived Syrian refugee families. This method allows participants to share descriptive accounts of subjective experiences of situations that facilitate or hinder a particular goal and was used successfully in a similar research examining the role of cultural brokers facilitating the adaptation of refugee children and families in schools (Yohani, 2013). Focus group discussions were approximately 2 hours each, 
led by a research team member and supported by a research assistant who audio recorded and took notes during the session. During each focus group, guiding questions were used to help brokers describe an incident (e.g., what happened, who was present, what type of psychosocial need/challenge was addressed, what the broker did during the incident, what was most challenging, and what was most helpful in dealing with the need/challenge), and to facilitate a shared conversation based on the presented case (e.g., what does this case tell us about the families' experiences, what does this case tell us about the work of brokers).

Individual interviews: Six individual semi-structured interviews, approximately 90 minutes in length, were conducted to further expand on the emerging findings from the five focus groups. Six of the nine cultural brokers participated in the interviews, and the three who did not, either did not have time to do so or felt that they had adequately covered their cases in the focus groups.

\section{Analysis}

Focus groups and interviews were transcribed verbatim and thematically analyzed using Braun and Clarke's (2006) guidelines. Although analysis was concurrent with data collection and built on key ideas as they emerged, a focused analysis of all the data was conducted after data collection was complete (Mayan, 2009). After the graduate research assistant completed the first level of analysis, the research team met a number of times to analyze and reflect on the focus groups and interviews to identify the psychosocial needs and challenges experienced by families and (b) the activities/ways that cultural brokers addressed these needs to support the psychosocial adaptation of families. Data were first coded and then grouped together to form thematic categories. Once key categories were identified, they were presented to the nine participating cultural brokers to facilitate a final contextualized interpretation of the findings, a typical practice in CBPR (Parker, Margolis, Eng, \& Henriquez-Roldan, 2003). For the purposes of this article, another analytical step was introduced whereby a research assistant reviewed the themes in relation to the RAISED model which was developed specifically to help educators understand the experiences of young refugee and immigrant children. This was followed by a series of research team meetings in which the three authors engaged in an in-depth examination and reflection of the preliminary mapping of the themes onto the RAISED model. The reflective process was guided by the desire to identify the Syrian refugee families with young children's experiences, shared by the cultural brokers, that could be helpful to educators in providing culturally relevant early learning experiences for the children and their families while using the RAISED model.

\section{Results and Discussion}

The following section integrates examples of challenges and strengths synthesized from our research findings within the five themes related to the RAISED model. Challenges included: language, ongoing safety issues, equitable access to services, and social isolation. Strengths included: language, social connection as a common strength and individual/family resilience. 


\section{Reveal Culture}

Consistent with the understanding of culture as everyday life and interactions in the context in which one lives, this factor highlights that educators can get a glimpse of children's cultural backgrounds through common everyday interactions such as greeting one another and expressing respect or gratitude. The model stresses that even children coming from the same region of the world may not have a common way of embodying cultural traditions. In addition, the model stresses that while some aspects of a person's culture may appear to be quite obvious, such as language, food and clothing, other less visible aspects of their culture like parent's beliefs about child development, called by Super and Harkness (2002) "parenteral ethnothories" (p. 270) or how play is valued in the parents' culture, have greater impact on children's everyday life. "Culturally-influenced behaviours and actions that may be seen as odd or problematic in one context may be cherished, necessary, and meaningful in another context" (Georgis et al., 2017, p. 12), making it important to identify, understand, and respect the deeper meaning behind these behaviours. Not having a common language makes it more difficult for both teachers and families to reach such an understanding. In such circumstances, teachers are likely to rely solely on their observations to understand families' challenges and cultural expectations of their child. Without cultural brokers who can help understand culturally shaped expectations and behaviours, however, teachers may interpret incorrectly children behaviors, as in Usman's study (2012) that found elementary school teachers in a Canadian school to take newcomer children's avoidance of direct eye contact with adults as a sign of disrespect and lack of attentiveness to school matters.

\section{Language as a Potential Barrier}

Throughout the larger study, families noted experiences where having a first language other than English, or not knowing any English at all was a barrier for them in adjusting to life in Canada.

"I feel like the kids here have a lot on their shoulders because a lot of the parents are illiterate even in their first language, so they're expecting their grade 3ers and grade 4 children to read the mail and make their parents understand what's being said." (Broker 4; Interview)

Youth and parents in our study were noted to struggle with finding jobs and pursuing their career aspirations because they were having difficulty either speaking English fluently enough or achieving the proper English credits for post-secondary schooling. Often, families were met with circumstances where they had to interact with someone or navigate Canadian systems when they were unable to understand the other person, such as not being able to understand one's doctor, a police officer, or teacher.

"Because of the language barrier, I felt that families were not 100\% involved with the school." (Broker 8; Interview)

In our study, the cultural brokers were, above all, the trusted person to accompany the family members to doctor's appointments, appointments with developmental or speech and language specialists, special education consultants, etc., and to translate as well as interpret the meaning of the conversations. Language as a barrier within the school system was reported by parents as being unable to understand what is required of them, filling out school forms or understanding teacher's homework requests. Children were struggling to understand and complete their work because they did not understand what was being asked of them. 


\section{Language as a Strength}

There are many positive aspects to having families maintain a strong first language other than English, including families' abilities to pass on their cultural knowledge and customs to their children, children learning second language more effectively (Kirova \& Paradis, 2011), and maintaining strong familial and community connections, which leads to better overall wellbeing, during early resettlement. However, in the early settlement period, the families' priority was not maintaining their children's first language. In fact, as with other immigrant and refugee children and their parents, Syrian families we were collecting information about, attended classes to learn the English language so that they can more effectively navigate Canadian systems. However, in the early resettlement stage, it was still beneficial for them to have access to professionals who speak their first language, as was in the case of several of our families who had access to psychiatrists, doctors, lawyers, and store owners who spoke their first language. For children too, being able to speak Arabic with other children in school, including their siblings, was important for their social adaptation.

One of the biggest struggles for educators is that they often do not have access to, or deep knowledge of, their students' cultures, or their status (i.e., immigrant class, refugee, asylum seeker, etc.) as this is not something that is typically inaccessible to educators unless revealed directly by the families (Miller, Ziaian, \& Esterman, 2017). Given the language barriers during early resettlement, accessing the wealth of knowledge and experience of cultural brokers is extremely beneficial. By talking with the children and their families about their culture through and with cultural brokers, educators will reach a better understanding of each child's needs and how they can best be met in a holistic and inclusive manner. The role of the cultural brokers is to guide both the parents and the teachers to understand that "parents' conceptions of competence and their corresponding behaviors can conflict with mainstream (school) conceptions" (Kağitçibaşi, 2007, p. 74). For example, families' emphasis on social competence as expressed by showing respect for elders is in contrast with schools' emphasis on cognitive competence (Nsamenang, 2009), which can create misaddressing between parents and educators. In referring specifically to Early Childhood Education practices, Cannella (1997) points out that "child development theories have fostered dominant ideologies and created privilege for those in power. Examples include establishment of hierarchical stages and the privileging of logical thought" (p. 63).

\section{Acknowledge Pre-Migration Experiences}

This factor emphasizes the need to educators to understand how every immigrant and refugee family has experiences that happened prior to their migration to Canada that may impact their behaviours and actions (Georgis et al., 2017). The pre-migration period includes three district stages: pre-departure, flight, and first asylum (Merali, 2008). During the flight stage, children are often exposed to traumatic events in their home countries, including violence and separation from loved ones (Hassan et al., 2015) as well as disruptions in schooling and normal flow of life as families leave behind all their possessions when fleeing. The first asylum stage, often at a neighbouring country or refugee camp, presents a new set of challenges including food shortage, lack of any employment opportunity, transportation, inability to provide sufficient documentation for registration in school, school fees, lack of residency status, and languagerelated issues (Human Rights Watch, 2016). The effects of pre-migration experiences, such as Journal of Contemporary Issues in Education, 2019, 14(1), pp. 13-32. 
war and conflict, can impact children in many different ways. Refugee children often face several psychosocial issues such as Post Traumatic Stress Disorder (PTSD), depressive symptoms and anxiety (Murray, 2016; Hadfield et al., 2017), bodily complaints, withdrawal, attention issues, a generalized sense of fear, irritability and agitation, increased dependency on others, and interpersonal challenges (Henley \& Robinson, 2011) that are often not attended to or even acknowledged as such. Acknowledging these journeys and experiences can provide important information about the person or family's background, which can lead to a better understanding of their beliefs and actions, and the development of effective ways to navigate their experiences.

\section{Ongoing Safety Concerns as a Common Barrier}

Without understanding the pre-migration experiences, educators may see the symptoms of these experiences in children at school through behaviors like selective mutism, separation anxiety, and acting-out as related to cognitive delays or issues on a behavioral disorder spectrum, when in reality they may be suffering from the effects of previous traumatic experiences or current retraumatization. In one case from our study, a family was advised to do some outdoor activities by a physician in an effort to combat the stress they were experiencing as a result of trauma they had experienced in their home country. The family went fishing together and were stopped by a police officer on their way home, who tried to communicate to them that they were not allowed to keep the fish and needed to release them back into the water. The family believed that they were about to be shot by this officer for breaking the law, as this was what would have happened in their pre-migration experiences, which resulted in the family being re-traumatized. In particular, the family's young child was so shocked that they developed selective mutism for a period of time.

"So, from that day...their young son was speechless, like he got in shock, he couldn't speak for day and a half." (Broker; Focus Group 3)

If educators take the time to understand the child and family's pre-migration experiences, they will be better able to understand the source of the child's behaviours at school and be better equipped to effectively work with them.

\section{Identify Post-Migration Systemic Barriers}

This factor of the RAISED between Cultures model stresses that despite arriving at a safe place, the first few years of the resettlement process in a new country can be fraught with hardships. Social isolation, perceived or real discrimination, and poverty, among others are experiences common to refugee and immigrants. For example, even though the official level of poverty among immigrant and refugees in Canada is unclear, one report states that it is around 34\% (Coker, 2017), with another study reporting that one fifth of immigrants face discrimination once they've arrived in Canada (Nangia, 2013). In addition to language, one of the more difficult barriers to navigate are systemic barriers, which occur when systems such as social, educational, or health services "have practices, processes/procedures, and beliefs that do not take into account the social, cultural, and language realities of all families and may prevent meaningful participation and equitable access to programs and services" (Georgis et al., 2017, p. 16). Identifying these post-migration systemic barriers allows for better understanding of the stressors 
that these families face on a daily basis, which in turn can lead to the development of better strategies for facing these stressors.

\section{Equitable Access to Services as Common Barrier}

Several of the families in our study identified issues with the health care system letting children with disabilities fall through the cracks, financial and welfare systems refusing support to families in need, and the education system threatening a child with suspension instead of trying to work with the family to identify how to work more effectively with the child.

As described elsewhere (Yohani et al., 2019), one of the families was struggling to access appropriate health care for their severely disabled children. Although two of the youngest children had been diagnosed with severe mental/physical disabilities by a United Nations medical officer prior to arrival in Canada, the family had not accessed any specialist or disability services despite being in Canada for 10 months. A local primary care physician had not released medical information to a specialist because the family had not paid for health service. They felt that they were not being treated like Canadians and were not getting the quality healthcare services they were hoping for: "They say we came here, we deserve to get the Canadian service with Canadian specialists, why are they referring us to the community doctors and they believe they are not professional enough." (Broker; Focus Group 1). Another family that had been in Canada for one year, had a child with a medical condition (Thalassemia) that does not qualify for supports and services for children with disabilities so the family, with the help of the cultural brokers who supported them kept facing institutional barriers." It's kind of difficult to have these doors...close when you're trying to support them..." (Broker; Focus Group 1).

The disconnect between the child and family's personal and social environments and the systemic environments that were intended to support them has left many of these children and families without the support that they need to successfully navigate and integrate into Canadian culture.

\section{Social Isolation as a Common Barrier}

Many families in our study reported experiencing feelings of social isolation and loneliness after coming to Canada, which occurred through various avenues such as not having people who share aspects of their culture in their living area, feeling unable to connect with people who primarily speak English, and missing loved ones from Syria. In one of the cases, the family was dealing with regular visits to the doctor for the mother's gestational diabetes as well as for the children's complex health challenges and was under a lot of distress. The father was responding to the stress by having anger bouts, so the family had to move living locations to be closer to the hospital for their children's weekly appointments. As a result of the move, the family became isolated and disconnected from other resources that were important to their overall sense of wellbeing, like community centres, friends, and cultural opportunities. This family was forced to choose between having access to healthcare for their children and having access to social supports, as a result the children having a complex medical condition. In another case, a young mother felt so isolated, feeling caught "between four walls" that she suffered an acute episode of depression with psychosomatic features, resulting in not being able to raise her hands to lift the baby and had to be taken to hospital. 
"They said okay, you know what, you are depressed. So I said, what's wrong? She said, I'm just imagine, this is what my life [is]. Children and home, in between four walls. Really there is nothing and I'm so tired I don't know what to do." (Broker; Focus Group 2)

The effects of post-migration systemic barriers can impact children in various ways, such as children suffering from bullying (e.g., Closs, Stead, Arshad, \& Norris, 2001) may affect their school attendance, or children whose parents are struggling at home may be experiencing a lot of stress which may translate to anxious or acting-out behaviours in school. Much like with acknowledging pre-migration experiences, by identifying the post-migration systemic barriers that may be affecting a child and their family, educators will be better able to understand the source of a child's behaviours and take actions to remedy the issue so that the child will be better able to engage in the social and learning experiences that should be the focus of every child's school experience.

\section{Support Family and Community Strengths}

This factor highlights the importance of recognizing and supporting the many strengths that immigrant and refugee families bring with them, such as resilience, hope, aspirations, strong community and familial networks, cultural wealth, first language, and bi-multi-lingualism (Georgis et al., 2017). It is vital to recognize and support these strengths because they enable these families to overcome the many barriers that they face as a result of their pre-migration experiences and post-migration barriers. For example, maintaining one's first language can help them to strengthen bonds and communication within their family and community and help children with the developments of their second language, which directly combats the aforementioned barriers of social isolation and language (Georgis et al., 2017).

\section{Social Connection as a Common Strength}

Several of the cases in our study highlighted the importance of having social connection to one's community in increasing children and family's overall sense of well-being. Social connection can be seen in immigrant and refugee children and families through connection to their family and extended family, cultural community, like attending community events and engaging in cultural practices, and the wider community, such as through taking English classes and engaging with people whose first language is English. Children often experience social connection through avenues such as attending school, interacting with their cultural community, and attending youth groups with other children. Children and families who have a strong sense of social connection are able to be more independent, self-reliant, and resilient than those who do not (LeMoine \& Labelle, 2014), as illustrated in the previous section where social isolation was noted to be a serious barrier for these children and families.

Immigrant and refugee children and families possess a lot of strengths that are sometimes overlooked, like the strong support their extended family can provide, or they are simply not identified as strengths, such as their multilingualism. Strengths that children make use of in the classroom include their ability to develop social connections, use of their first language as a stepping stone to more effectively learning their second language (Kirova \& Paradis, 2011), and innate knowledge of their own cultural practices that they sometimes demonstrate in play. As Kirova's (2010) study of refugee children's dramatic play demonstrates, children play "cultural Journal of Contemporary Issues in Education, 2019, 14(1), pp. 13-32. 
scripts" such as serving tea or shopping in a market and teachers can use these play episodes to see how much children know about their cultural worlds. Educators who can identify and support a child's strengths in the classroom can use these to increase a sense of belonging and acceptance and ultimately facilitate successful social and academic outcomes.

\section{Establish Connections between Environments}

This factor of the RAISED between Cultures model emphasizes the importance of creating connections between the immigrant and refugee children and family's home and broader community environments. Families are able to experience, share, and maintain their heritage culture and cultural identity through their home and ethnocultural community, while also being able to experience Canadian culture and develop a bicultural identity through broader community experiences (Georgis et al., 2017). Establishing connections between these two environments helps immigrant and refugee families to better transition to life in the new country.

\section{Resilience as a Common Strength}

In every case we examined in our study, we found the children and their families to be very resilient and often independent in navigating their social environments, such as in cases where many parents pursued schooling as soon as possible upon arrival to Canada as well as in the case where a father decided to independently stand up for himself in court when he felt that a ticket offence he was given was unjust. Almost every family we examined either reached out or was receptive to cultural brokers for help in establishing connections between themselves and their social environments, one family in which the father had actually already researched and developed a list of potential agencies that could help him when he initially contacted a cultural broker. These families' willingness to push through the many barriers that they face and ability to ask for direction when they need help establishing connections with other systems and environments speaks to the incredible resilience that these children and families possess.

Educators work within one system that is vitally important to immigrant and refugee children and their families - the education system. All too often these children are misunderstood within the education system as a result of a disconnection between their home and school environments, as was the case where one of our families had a child who was being threatened with suspension as a result of a misunderstanding between the child and school. In this particular case, a cultural broker intervened to establish this missing connection and remedy the issue at hand without any drastic actions having to be taken. When it comes to early childhood education settings which are usually the first point of contact with the host country's culture, establishing connections with the families of their immigrant and refugee children is vital for the wellbeing of the children. Cultural brokers are invaluable resource for both the families and the educators, as they are able to provide a variety services that are critical to the success of this process. They can act as a translator, helping to clear up miscommunications and cultural differences, prove ideas for how to bridge and connect with the children and families, and ensure that the family and the educators support the child's educational experiences and work towards soother home/school transition. 


\section{Determine Child Outcomes Together with Families}

The final factor of the RAISED between Cultures model stresses the importance of working together with immigrant and refugee families to determine their outcomes and goals and how to best support these goals (Georgis et al., 2017). As noted earlier, culture is complex and dynamic and each family's cultural experience will vary, making it important to work through the RAISED between Cultures model factors to ensure that each family's unique experiences, strengths, and needs are being addressed.

\section{Assessing Barriers to Accessing Services}

Identifying challenges and barriers to accessing non-academic supports can be difficult for educators. However, when working closely with families and their community supports, an increased understanding of cultural and language barriers can facilitate supports. In one of the cases in our study, a mother who was identifying as struggling with depression, was not interested in mental health supports. Upon further consultation with the family, it became clear that she felt like there was no time for her personal supports while she was caring for her children and because of the English language barrier. The intervention for this family included supporting the mother to attend both English language classes and community group supports. In another case, one young boy was angry about being taken out of English-Language Learning classes and being put into mainstream English classes because he felt that he was not ready for this change. The intervention for this family was addressed with the assistance of a cultural broker.

\section{Involving Family in Decision Making}

In our study, we noted instances of cultural brokers working alongside families to facilitate decision making that influenced child outcomes. In one case, a broker modelled connecting to children with severe mental disabilities as a way to open possibilities for their father by showing a different approach to working with disabilities (vs a cultural approach that was limiting). "When I met them [the children] they sit beside me. We connected emotionally, and I was telling the father, you see them as they are mentally disabled, but if you focus ... you will see how emotionally they can connect with you. Cause he was telling me, don't bother..." (Broker; Focus Group 1). In another case, two brokers worked closely with a family to facilitate the decision for the family to move to another part of the city to be closer to health supports for their children with complex health needs.

\section{Summary and Conclusions}

Meeting the multiple needs of refugee families and young children in early learning and care contexts is complex. Drawing on findings from our study on the psychosocial adaptation of Syrian families with young children, we can see how the strengths and challenges faced by these families fit well with the five areas of the RAISED between Cultures framework. More specifically, the RAISED between Cultures framework added multiple layers of understanding of the everyday life of the Syrian refugee families that directly influence young children. As Bronfenbrenner (1992) pointed out, reciprocal interactions between a developing child and persons, objects, and symbols in the external environment, such as learning a new skill or playing are called "proximal processes" and are the primary engines of development 
(Bronfenbrenner, 1992). While for non-refugee children such experiences are likely to contribute to development through processes of progressively more complex interactions that occur on a regular basis over extended periods of time (Bronfenbrenner \& Ceci, 1994), for recent refugee and immigrant children the possibilities for such interaction to generate transferable skills and knowledge appeared to be somewhat limited. Parents' struggles with navigating multiple systems in their host country, including the healthcare and education systems, contributed to the stress and its manifestation in various behaviors at home that could have negative impact on children's formative years. The issues faced by their parents in a new unfamiliar context, therefore may have an overall negative emotional impact on children's ability to relate to themselves and others. Thus, the model, showed promise as a holistic model that can guide a collaborative process of bringing together educators and other key stakeholders to support refugee and immigrant children and families.

While our study focused on the role of cultural brokers in facilitating the adaptation of Syrian refugee families, our results provide evidence for the application of the model for educators and other school personnel. Importantly, the examples speak to the complex needs and strengths of families and children, and the need for holistic models to support children. That is, models that see children in context, including the various systems that provide supports and resources, the various barriers and challenges that parents encounter, and cultural values and expectations. It encourages educators to develop critical awareness of the multiple and complex conditions, contexts and factors that influence young refugee children's lives and development. In addition, it provides a way to interrupt the "at risk" discourse that positions them only as needy and powerless and promotes teaching and learning practices that intentionally integrate and validate the rich linguistic and cultural experiences and perspectives of children and families from diverse backgrounds.

\section{Acknowledgements}

The authors wish to acknowledge the support received by SSHRC for this research project. The authors also wish to acknowledge the invaluable contributions of the partner organizations for the research project, and most of all, the contributions of the cultural brokers who devoted many hours of their valuable time to participate in this research. 


\section{References}

Ahmed, A., Bowen, A., \& Xin Feng, C. (2017). Maternal depression in Syrian refugee women recently moved to Canada: A preliminary study. BMC Pregnancy and Childbirth, 17, 111. https://doi.org/10.1186/s12884-017-1433-2

Allman, D., Myers, T. \& Cockerill, R. (1997). Concepts, definitions and models for communitybased HIV prevention research in Canada. Toronto: University of Toronto.

Bates, L., Baird, D., Johnson, D. J., Lee, R. E., Luster, T., \& Rehagen, C. (2005). Sudanese refugee youth in foster care: The "lost boys" in America. Child Welfare Journal, 84, 631648.

Betancourt, T. S., \& Khan, K. T. (2008). The mental health of children affected by armed conflict: Protective processes and pathways to resilience. International Review of Psychiatry, 20, 317-328. https://doi.org/10.1080/09540260802090363

Betancourt, T. S., Newnham, E. A., Layne, C. M., Kim, S., Steinberg, A. M., Ellis, H., \& Birman, D. (2012). Trauma history and psychopathology in war-affected refugee children referred for trauma-related mental health services in the United States. Journal of Traumatic Stress, 25, 682-690. https://doi.org/10.1002/jts.21749

Braun, V. \& Clarke, V. (2006). Using thematic analysis in psychology. Qualitative Research in Psychology, 3, 77-101. https://doi.org/10.1191/1478088706qp063oa

Bronfenbrenner, U. (1979). The ecology of human development: Experiments by nature and design. Cambridge, MA: Harvard University Press.

Bronfenbrenner, U. (1994). Ecological models of human development. In International Encyclopedia of Education (2nd ed., Vol. 3). Oxford: Elsevier.

Bronfenbrenner, U. (1992). Ecological systems theory. In R. Vista (Ed.), Six theories of child development: Revised formulations and current issues (pp. 187-249). London: Jessica Kingsley.

Bronfenbrenner, U., \& Ceci, S. J. (1994). Nature-nurture reconceptualized in developmental perspective: A bio-ecological model. Psychological Review, 101(4), 568-586. https://doi.org/10.1037/0033-295X.101.4.568

Bronfenbrenner, U., \& Evans, G. W. (2000). Developmental science in the 20th century: Emerging questions, theoretical models, research designs and empirical findings. Social Development, 9(1), 115-125. https://doi.org/10.1111/1467-9507.00114

Bronfenbrenner, U., \& Morris, P. A. (1998). The ecology of developmental processes. In R. M. Lerner (Ed.), Handbook of child psychology: Vol.1. Theoretical models of human development (5th ed., pp. 535-584). New York: Wiley.

Brosinsky, L., Georgis, R., Gokiert, R., Mejia, T., \& Kirova, A. (2018). RAISED between cultures: New resources for working with children of immigrant or refugee background. Childhood Education, 94(2), 18-27. https://doi.org/10.1080/00094056.2018.1451686

Cannella, G., S. (1997). Deconstructing early childhood education: Social justice \& revolution. New York: Peter Lang.

Carter, T.A., \& Osborne, J. (2009). Housing and neighborhood challenges in refugee resettlement in declining inner city neighborhoods: A winning case study. Journal of Immigrant \& Refugee Studies, 7, 308-327. https://doi.org/10.1080/15562940903150097

Citizenship and Immigration Canada (2017). \#WelcomeRefugees: Key figures. http://www.cic.gc.ca/english/refugees/welcome/milestones.asp 
Closs, A., Stead, J., Arshad, R., \& Norris, C. (2001). School peer relationships of 'minority' children in Scotland. Child: Care, Health and Development, 27(2), 133-148. https://doi.org/10.1046/j.1365-2214.2001.00194.x

Coker, B. (2017). Canada must pay attention to refugees in poverty. Citizens for Public Justice. Retrieved from https://cpj.ca/canada-must-pay-attention-refugees-poverty

Cummins, J. (1991). The development of bilingual proficiency from home to school; A longitudinal study of Portugees-speaking children. Journal of Education, 173(2), 85-98. https://doi.org/10.1177/002205749117300207

Cummins, J. (2012), Foreword. Lingustically appropriate practices: A guide for working with young immigrant children, ix-xiv, Toronto, ON: University of Toronto Press.

Flanagan, J. C. (1954). The critical incident technique. Psychological Bulletin, 51, 327-358. https://doi.org/10.1037/h0061470

Gauvain, M., \& Parke, R. D. (2010). Socialization. In M. H. Bornstein (Ed.), Handbook of cultural developmental science (pp. 239-258). New York, NY: Psychology Press.

Georgis, R., Brosinsky, L., Mejia, T., Kirova, A., Gokiert, R., \& Knowledge Exchange Advisory (2017). RAISED between cultures: A knowledge and reflection guidebook for intercultural practice in the early years. Edmonton, AB: Community-University Partnership, University of Alberta.

Ghumman, U., McCord, C.E., \& Chang, J.E. (2016). Posttraumatic stress disorder in Syrian refugees: A review. Canadian Psychology, 57(4), 246-253.

https://doi.org/10.1037/cap0000069

Hadfield, K., Ostrowski, A., \& Ungar, M. (2017). What can we expect of the mental health and well-being of Syrian refugee children and adolescents in Canada? Canadian Psychology, 58(2), 194-201. https://doi.org/10.1037/cap0000102

Hassan, G., Kirmayer, L. J., Ventevogel, P., Mekki-Berrada A., Quosh, C., el Chammay, R., Deville-Stoetzel, J.B., Youssef, A., Jefee-Bahloul, H., Barktell-Oteo, A., Coutts, A., \& Song, S. (2015). Culture, context and the mental health and psychosocial wellbeing of Syrians: A review for mental health and psychosocial support staff working with Syrians affected by armed conflict. Geneva: UNHCR.

Henley, J., \& Robinson, J. (2011). Mental health issues among refugee children and adolescents. Clinical Psychologist, 15, 51-62. https://doi.org/10.1111/j.1742-9552.2011.00024.x

Heydon, R., M., \& Iannacci, L. (2008). Early childhood curricula and the de-pathologizing of childhood. Toronto, ON: University of Toronto Press. https://doi.org/10.3138/9781442686243

Human Rights Watch. (2016). “Growing up without an education”: Barriers to education for Syrian refugee children in Lebanon. Retrieved from https://www.hrw.org/sites/default/files/report_pdf/lebanon0716web_1.pdf

Immigration, Refugees and Citizenship Canada (2018). Immigration, Refugees and Citizenship Canada Departmental Plan 2018-2019 Retrieved from:

https://www.canada.ca/en/immigration-refugees-citizenship/corporate/publicationsmanuals/departmental-plan-2018-2019/departmental-plan.html

Israel, B. A., Schulz, A. J., Parker, E. A., Becker, A. B., Allen, A. J., \& Guzman, J. R. (2003). Critical issues in developing and following community based participatory research principles. In M. Minkler \& N. Wallerstein (Eds.), Community based participatory research for health (pp. 53-76). San Francisco, CA: Jossey Bass. 
Jezewski, M. (1990). Culture brokering in migrant farmworker health care. Western Journal of Nursing Research, 12, 497-513. https://doi.org/10.1177/019394599001200406

Kâgitçibasi, Ç. (2007). Family, self, and human development across cultures: Theory and applications (2nd ed.). New Jersey: Lawrence Erlbaum.

Kanji, Z., \& Cameron, B. L. (2010). Exploring the experiences of resilience in Muslim Afghan refugee children. Journal of Muslim Mental Health, 5(1), 22-40.

https://doi.org/10.1080/15564901003620973

Kirova, A. (2010). Children's representations of cultural scripts in play: Facilitating transition from home to preschool in an intercultural early learning program for refugee children. Diaspora, Indigenous and Minority Education, 4, 74-91. https://doi.org/10.1080/15595691003635765

Kirova, A., \& Paradis, J. (2011). The role of an intercultural early learning program for refugee and immigrant children on the development of their L1 and L2 skills and abilities: Final report. Retrieved from https://policywise.com/wpcontent/uploads/resources/2016/07/Sept10Authorfinalreport1pdf.pdf

Klingman, A. (2002). Children under stress of war. In A. M. La Greca, W. K. Silverman, E. M. Vernberg, \& M. C. Roberts (Eds.), Helping children cope with disasters and terrorism (pp. 359-380). Washington, DC: American Psychological Association. https://doi.org/10.1037/10454-015

Lake, S. (2016). Not so universal health care: The neglect of immigrant and refugee health in Canada. The University of British Columbia Medical Journal, 7(2), 38-39.

LeMoine, K., \& Labelle, J. (2014). What are effective interventions for building resilience among at-risk youth? Region of Peel. Retrieved from: https://www.peelregion.ca/health/library/pdf/rapid-review-resilience-at-risk-youth.pdf

Mayan, M. (2009). Essentials of qualitative inquiry. Walnut Creek, CA: Left Coast Press.

Merali, N. (2008). Social conditions and refugee mental health before and after migration. In M. K. Zimmermann (Ed.), Political refugees: Social conditions, health, and psychological characteristics (pp. 1-31). New York: Nova Science Publishers.

McFarlane, C. A., Kaplan, I., \& Lawrence, J. A. (2011). Psychosocial indicators of wellbeing for resettled refugee children and youth: Conceptual and developmental directions. Child Indicators Research, 4, 647-677. https://doi.org/10.1007/s12187-010-9100-4

Miller, E., Ziaian, T., \& Esterman, A. (2017). Australian school practices and the education experiences of students with a refugee background: A review of the literature. International Journal of Inclusive Education, 22(4), 339-359. https://doi.org/10.1080/13603116.2017.1365955

Murray, J. S. (2016). Displaced and forgotten child refugees: A humanitarian crisis. Journal for Specialists in Pediatric Nursing, 21(1), 29-36. https://doi.org/10.1111/jspn.12133

Nangia, P. (2013). Discrimination experienced by landed immigrants in Canada. Ryerson Centre for Immigration and Settlement: Working Papers, 2013(7), 1-15. Retrieved from https://www.ryerson.ca/content/dam/rcis/documents/RCIS_WP_Parveen_Nangia_No_20 13_7.pdf

Nsamenang, A. B. (2009). Cultures in early childhood care and education. In M Fleer, M. Hedegaard, \& J. Tudge (Eds.), Childhood studies and the impact of globalization: Policies and practices at global and local levels (pp. 24-45). New York, NY: Routledge. OHCHR (2019). Convention on the rights of the child. United Nations Human Rights. Office of the High Commissioner. http://www.ohchr.org/EN/ProfessionalInterest/Pages/CRC.aspx 
Oppedal, B. (2006). Development and acculturation. In D. L. Sam \& J. W. Berry (Eds.), The Cambridge handbook of acculturation (pp. 97-112). Cambridge, NY: Cambridge University Press. https://doi.org/10.1017/CBO9780511489891.010

Özer, S., Şirin, S., \& Oppedal, B. (2013). Bahçeşehir study of Syrian refugee children in Turkey. Retrieved from https://www.fhi.no/globalassets/dokumenterfiler/moba/pdf/bahcesehirstudy-report.pdf

Parker, E., Margolis, L.H., Eng, E., \& Henriquez-Roldan, C. (2003). Assessing the capacity of health departments to engage in community-based participatory public health. American Journal of Public Health, 93(3), 472-476. https://doi.org/10.2105/AJPH.93.3.472

Saile, R., Ertl, V., Neuner, F., \& Catani, C. (2014). Does war contribute to family violence against children? Findings from a two-generational multi-informant study in Northern Uganda. Child Abuse \& Neglect, 38, 135-146. https://doi.org/10.1016/j.chiabu.2013.10.007

Skutnabb-Kangas, T. (2002). Language Policies and Education: The Role of Education in Destroying or Supporting the World's Linguistic Diversity. Retrieved from: http://www.linguapax.org/wp-content/uploads/2015/07/CMPL2002_Plenari_TSkutnabbKangas.pdf

Soykoek, S., Mall, V., Nehring, I., Henningsen, P., \& Aberl, S. (2017). Post traumatic stress disorder in Syrian children of a German refugee camp. The Lancet, 10072(389), 903-904. https://doi.org/10.1016/S0140-6736(17)30595-0

Super, C. M., \& Harkness S. (2002). Culture structures the environment for development. Human Development, 45(4), 270-274. https://doi.org/10.1159/000064988

Tol, W. A., Song, S., \& Jordans, M. J. D. (2013). Annual research review: Resilience and mental health in children and adolescence living in areas of armed conflict-A systematic review of findings in low- and middle-income countries. Journal of Child Psychology and Psychiatry, 54, 445-460. https://doi.org/10.1111/jcpp.12053

Tudge, J. (2008). The everyday lives of young children: Culture, class, and child rearing in different societies. Cambridge, NY: Cambridge University Press. https://doi.org/10.1017/CBO9780511499890

United Nations High Commissioner for Refugees (UNHCR) (2018, March 9). Syria conflict at seven years: "A colossal human tragedy". [Press Release]. Retrieved from http://www.unhcr.org/news/press/2018/3/5aa1ad2e4/syria-conflict-7-years-colossalhuman-tragedy.html

Usman, L., M (2012). Communication disorders and the inclusion of newcomer African refugees in rural primary schools of British Columbia, Canada. International Journal of Progressive Education, 8(2), 102-120.

Wong Fillmore, L. (1991). When learning a second language means losing the first, Early Childhood Research Quarterly, 6, 323-46. https://doi.org/10.1016/S08852006(05)80059-6

Yohani, S. C. (2013). Educational cultural brokers facilitating the school adaptation of refugee children and families: Challenges and opportunities. Journal of International Migration and Integration, 14(1), 61-79.

Yohani, S. C. (2015). Applying the ADAPT psychosocial model to war-affected children and adolescents. SAGE Open, 1-18. https://doi.org/10.1177/2158244015604189 
Yohani, S., Kirova, A., Georgis, R., Gokiert, R., Mejia, T., \& Chiu, Y. (2019). Cultural brokering with Syrian refugee families with young children: An exploration of challenges and best practices in psychosocial adaptation. Journal of International Migration \& Integration. (online). https://doi.org/10.1007/s12134-019-00651-6 